\title{
Publisher Correction: Giant photothermal nonlinearity in a single silicon nanostructure
}

Yi-Shiou Duh, Yusuke Nagasaki, Yu-Lung Tang, Pang-Han Wu, Hao-Yu Cheng, Te-Hsin Yen, Hou-Xian Ding, Kentaro Nishida, Ikuto Hotta, Jhen-Hong Yang (1), Yu-Ping Lo, Kuo-Ping Chen, Katsumasa Fujita, Chih-Wei Chang (1), Kung-Hsuan Lin (1), Junichi Takahara (1) \& Shi-Wei Chu (1)

Correction to: Nature Communications https://doi.org/10.1038/s41467-020-17846-6, published online 14 August 2020.

The original version of this Article contained an error in Fig. 4b, in which the $x$-axis label incorrectly read: "Time (s)". The correct form of the $x$-axis label of Fig. $4 \mathrm{~b}$ is: "Time (ns)".

This has been corrected in both the PDF and HTML versions of the Article.

Published online: 07 October 2020

Open Access This article is licensed under a Creative Commons Attribution 4.0 International License, which permits use, sharing, adaptation, distribution and reproduction in any medium or format, as long as you give appropriate credit to the original author(s) and the source, provide a link to the Creative Commons license,
and indicate if changes were made. The images or other third party material in this article are included in the article's Creative Commons license, unless indicated otherwise in a credit line to the material. If material is not included in the article's Creative Commons license and your intended use is not permitted by statutory regulation or exceeds the permitted use, you will need to obtain permission directly from the copyright holder. To view a copy of this license, visit http://creativecommons.org/licenses/by/4.0/.

(C) The Author(s) 2020 